\title{
The Elimination of Madagascar's Vanilla Marketing Board, 10 Years on
}

\author{
Olivier Cadot ${ }^{\mathrm{a}}$, Laure Dutoit ${ }^{\mathrm{b}}$ and Jaime de Melo ${ }^{\mathrm{c}, *}$ \\ ${ }^{a}$ HEC Lausanne, CERDI and CEPR \\ ${ }^{\mathrm{b}}$ Economic Commission for Latin America \\ ${ }^{c}$ Department of Economics, University of Geneva, \\ CERDI and CEPR
}

This paper explores how the elimination of Madagascar's Vanilla Marketing Board (VMB) in 1993 affected prices paid to farmers, incentives and indicators of poverty and inequality using household survey data and simulation analysis. Following the reforms, margins between FOB and farmgate prices have narrowed down, and the analysis of changes in poverty and inequality based on household surveys suggests a reduction in poverty and a muted supply response. A counterfactual analysis based on the observed reduction in intermediation margins shows that, however limited, increase in competition among intermediaries has contributed to raise purchase prices and the cash income of vanilla farmers. After taking into account the reduction in Madagascar's monopoly power on the world vanilla market implied by the elimination of the $V M B$, the induced rise in producer prices is estimated to have lifted about 20,000 individuals out of poverty.

JEL classification: $F 14,011,012$

\section{Introduction}

In most low-income countries, particularly in Sub-Saharan Africa (SSA), poverty is above all a rural phenomenon. Thus, reducing poverty means first and foremost raising the incomes of farmers. Although all farmers should ultimately benefit from pro-market reforms, those engaged in the production of cash crops, in particular,

* Corresponding author: Jaime de Melo. E-mail: demelo@unige.ch

(C) The author 2008. Published by Oxford University Press on behalf of the Centre for the Study of African Economies. All rights reserved. For permissions, please email: journals.permissions@oxfordjournals.org 
export ones, are most susceptible to be reached by the trade reforms adopted by many SSA countries since the 1990s. However, although the failure of pro-reform policies is by now well documented, much uncertainty remains on the effect of those reforms.

The wave of pro-market reforms of the 1990s appeared against a backdrop of widespread failure in government intervention. Although sometimes justified on theoretical grounds (as in the case of vanilla), marketing boards and stabilisation funds led to illfated outcomes documented in a growing body of well-documented case studies (see e.g., Krueger et al., 1988; Schiff and Valdes, 1992; Jaffee and Morton, 1995; McMillan et al., 2004). Reasons behind the failures are multiple. Export crops are often extracted from a narrow geographic and economic base, meaning few supplier countries and often, also, few intermediaries in the export trade. Those situations suggest a high potential for strategic interaction over the appropriation of rents (Bohman et al., 1996; McMillan 2001). Typically, particularly in SSA after independence, government intervention in the form of marketing boards ostensibly meant to exploit monopoly power externally and shelter farmer incomes from world-price volatility internally. However, weak public institutions associated with the failure of farmers to organise for the defence of their interests meant a widening wedge between FOB and farmgate prices, the difference being appropriated by various combinations of organised groups. In particular, export structures specialised in 'point-source' (as opposed to diffuse) natural resources such as vanilla proved strongly associated with weak public institutions and low growth (Isham et al., 2005).

Throughout the 1990s, along with complementary sectoral reforms (e.g., privatisation of processing, removal of price controls and taxes), marketing boards and stabilisation funds were largely eliminated throughout SSA, as was the case for vanilla when several decades of interventionist policies associated with what could be described as the Vanilla Marketing Board (VMB) were dismantled starting in 1993. In retrospect, reforms in SSA have met with varying degrees of success. If reform appraisal is sometimes complicated by the policies of importing countries (as in the case of cotton), domestic reforms deemed necessary have often been either slow, as in the case of the four major West African cotton producers (Baffes, 2005), or controversial, as in the case of cashew nuts in Mozambique (McMillan et al., 2003). 
Lacking the necessary household surveys before and after the reforms, it is hard to know how rural poverty has been affected by these reforms. With household surveys (1993, 1997, 1999, 2001) straddling the reforms when export taxation and the VMB were eliminated around 1995, Madagascar's vanilla reform is an exception. Yet, the 10 years since reform have featured several unforeseen events, renewed turbulence on the vanilla market and changes in the distribution of the gains from trade, which makes it a challenge to identify the distributional effects of the reforms, which is the focus of this case study.

Vanilla in Madagascar is a particularly interesting case to study the hurdles that reforms must overcome to be successful. The characteristics of the vanilla market and of vanilla preparation suggest sufficient externalities and market failures (e.g., asymmetric quality information) to justify intervention of the type that was initially set up. So if opportunistic behaviour could be controlled, cooperation among agents involved in the value chain leading to export would be optimal both to overcome market failures and to exploit its monopoly power on high-quality ('Bourbon') vanilla.

Thus, put in historical perspective, the argument for reform was not a welfare one, as transparent cooperation between all domestic agents would have been-taking the market-failure arguments at face value and putting the political environment's realities asideMadagascar's first best. Instead, the argument was essentially (i) a comparison of second-bests and (ii) of a distributional nature.

It was a comparison of second-bests because the pre-reform state of play was very far from the cooperative optimum, as the marketing board simultaneously expropriated vanilla farmers through very low farmgate prices while setting the FOB price substantially above the static revenue-maximising level even taking into account the reaction of followers (de Melo et al., 2000). The marketing board's perplexing behaviour implied that the argument for reform was to replace the unsustainable over-exploitation of a dwindling market power by its under-exploitation in an imperfectcompetition equilibrium on the domestic intermediation market.

The distributional aspect of the argument involved the redistribution of rents from urban elites (intermediaries and political beneficiaries) towards farmers. However, even at this high level of simplicity, the argument was less than straightforward as 
vanilla-growing farmers, although poor in absolute terms, were still relatively high up in the distribution of rural incomes. So ironically, reform, if successful, had the potential to 'widen' rural income inequality.

Following a description that details the organisation and market structure of the vanilla sector and highlights the characteristics of vanilla farmers revealed in the four household surveys used in this study in Section 2 and a summary of the key phases in the evolution of Madagascar's policies in the vanilla sector in Section 3, Section 4 launches into an assessment of the reforms. We adopt a two-pronged strategy. First, drawing on household surveys and several sources of price data, we look at price, quantity and incomedistribution indicators in the vanilla region which reveal a substantial reduction in the intermediation margins following the reforms and rather small impacts on income distribution and poverty, the latter result being largely attributable to the fact that vanilla is a rather small share of household income. These results prompted us to complement the household-based appraisal with a simulation model of the vanilla market leading to a counterfactual experiment in which we compare a current (i.e. calibrated) equilibrium with the one that would prevail under the old export-monopolycum-export-tax regime in which we resuscitate the VMB. This counterfactual plausibly corroborates the rise in farmgate prices observed in the data following the abolishment of the VMB. The simulated price and quantity effects from the counterfactual are then re-injected into estimates of the distribution of income to simulate the distributional and poverty implications of the elimination of the policies associated with the VMB. Conclusions follow in Section 5 .

\section{The Vanilla Sector}

Smuggled out of Mexico by Cortes in 1520, vanilla was introduced to the Réunion, then called Ile Bourbon, around 1793, but without the complementary bee that carried out the pollination. Vanilla production had to wait for the discovery of hand pollination in 1836. From then on, its cultivation for export to the Metropole was encouraged by colonial authorities, although for technical reasons; unlike other tropical crops, its production could never be carried out in large plantations. 
Low in bulkiness, vanilla has a high unit value and is highly differentiated across origins. Madagascar's vanilla is considered high quality because of its high vanillin content (1.5-2\%), and substitutability is low between beans of different origins ('Bourbon', which denotes beans from Madagascar, Comoros and Réunion, versus the Mexican, Java and Bali's 'Bourbon-like' quality). Vanilla is the only spice that benefits from a 'standard of identity' helping to shield it from competition by substitutes. Synthetic vanilla, which is cheaper than the natural one, accounts for the bulk of the overall vanilla market (about 20,000 tons per year, of which natural accounts for $10-15 \%$ ). Tonnages on the natural vanilla market have hovered between 1,500 and 2,500 tons per year worldwide with no clear trend. ${ }^{1}$

\subsection{Organisation and Market Structure ${ }^{2}$}

For what follows, it is useful to describe the three stages involved in the production of vanilla prior to exporting. Figure 1 shows these stages: (i) vanilla growing, which produces the 'green' beans; (ii) curing, the stage at which it develops its quality (flavour profile and natural vanillin content); (iii) packing (sorting, grading and tying in small homogenous bunches). Each stage requires specific skills.

Growing is highly labour-intensive, as crop husbandry requires 260 man-days per hectare during the first year and about 460 during the 4-8 years where plants reach maturity. Pruning and weeding are then supplemented by hand-pollination-which

${ }^{1}$ Like other primary products, natural vanilla faces a constant threat from technical change. For instance, a German flavour and biotech company, Symrise, was recently reported to have made advances in the development of natural vanillin by fermentation with genetically modified bacteria of Eugenol, the conventional (and cheap) source of artificial vanillin. Although European hostility towards GMOs has convinced Symrise's management to put its GM vanillin project temporarily on hold, once on the market, this technology could increase competition for natural vanilla (see www.genet-info.org).

2 This section draws from Blarel \& Dolinsky (1995). Ecott (2004) narrates the fascination with vanilla since the time when the Aztecs demanded vanilla as a tax from the people of the central and high plateaus of the country we now call Mexico. In addition to a history of vanilla's origins and its development, his book describes in great detail the organisation of vanilla production and its use by the flavouring industry (see the narrative of his visit to the Nielsen-Massey factory), and documents some of the clashes in the Madagascar's vanilla market (see Chapters 11 and 13). 


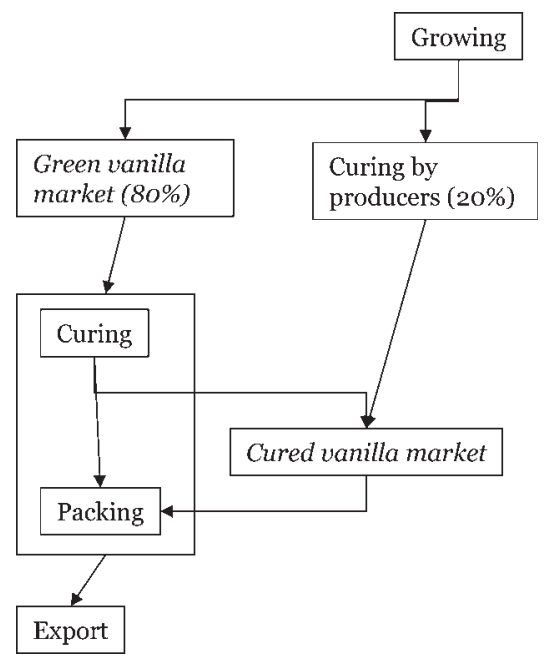

Figure 1: Organisation of the Vanilla Sector in Madagascar

means that each flower on the vine has to be pollinated by hand and at different times-and harvesting. ${ }^{3}$ Most workers engaged in growing belong to the family and very few producers turn to employed workers (Government of Madagascar (GOM), 2003). This is mostly due to the meticulous work required for vanilla production. With few purchased inputs (producers need very little equipment and pesticides are useless), entry and exit costs are low although plants require over three years to become productive, and growing conditions are rather exacting (small tracts of rich soil under the shade of trees).

Curing entails dipping beans in near-boiling water, then triggering an enzymatic reaction by alternate heating and 'sweating', which means boxing the beans and exposing them to sunlight. The process is repeated 10-20 times before the beans are left to dry outdoors for 2-3 months. By then, they possess a uniform dark colour and strongly smell of vanilla.

Once cured, vanilla beans are prepared, packed and stored in order to keep their flavour, a stage that is peculiar to Indian Ocean producers. The storage process, which can last up to two years, is

${ }^{3}$ Ecott (2004) is essential reading for anyone interested in the 'story' of vanilla. Chapter 4 describes the discovery of hand-pollination in La Réunion in the nineteenth century. 
risky, as vanilla can mould and weekly inspections are required. The required expertise creates a barrier to entry compounded by the cost of maintaining a high-value stock. Though it need not be the case, packers often export, and importers from the three main importing countries-the USA, France and Germany-keep close and lasting marketing contacts with exporters.

Several of a bean's quality characteristics are unobservable and largely determined by growing conditions, time of harvest and the curing process. This asymmetric information can make it tempting for individual growers and/or curers to free-ride, in particular by early harvest, giving rise to a prisoner's dilemma. ${ }^{4}$ The resulting market failure could in principle be addressed by a variety of market mechanisms, including vertical integration, branding or industry standards.

As a matter of fact, vertical integration between farming and processing is virtually nonexistent. If incentives to vertically integrate between curers and packers are stronger to overcome information asymmetries, they are still limited because the activities require specific skills. In the absence of vertical integration, the industry has developed weaker mechanisms to alleviate adverse-selection issues, such as the introduction of identification marks that remain visible after curing.

Virtually, all packers have traditionally been Malagasy companies, some owned by ethnic Chinese. Although in the mid-1990s there were about 45 packers, five of them largely controlled the business (Blarel and Dolinsky, 1995), and the top three exporters accounted for two-thirds of Madagascar's exports. This high concentration arguably resulted as much from government policies and rent-seeking as from economic rationality (marketing externalities and the like). Prior to its elimination, CAVAGI (French acronym for Vanilla Stabilization Fund) was the quasi-sole purchaser from the packers.

${ }^{4}$ Five months after flowering, vanilla beans have reached their optimal size but contain less than $1 \%$ of vanillin. In order to reach a vanillin content of about $2 \%$ (the norm for Bourbon vanilla), the beans must be harvested at least eight months after flowering. Fringe traders can thus be tempted to compete on collection dates. That is, if trader $i$ collects at date $t$, trader $j$ has an incentive to collect at date $t-1$. Depending on his discount rate, the farmer can be induced, in equilibrium, to sell his vanilla too early-though this competition can only take place over a short period-leading to rent dissipation pretty much like in patent races. 


\subsection{Vanilla Farming}

We now turn to a characterisation of vanilla farms on the basis of statistical information from Madagascar's four household surveys (EPM under their French acronym standing for 'Enquêtes Permanentes de Ménages'): 1993, 1997, 1999 and 2001 carried out in the country's six provinces (Table 1). Vanilla farming is concentrated on about 30,000 ha of plantations in the so-called SAVA zone (Sambava, Antalaha, Vohémar and Andapa) in the North-Eastern province of Antsiranana, with smaller numbers in the Toamasina province, thus covering two out of the six provinces. Owing to differences in coverage and sampling methods, comparisons across surveys are tricky (Paternosto et al., 2001), but will be carried out here since this is the only detailed micro data at our disposal to identify who the farmers are. Table 1 describes the geographical distribution of farming activities. Because of its labour-intensive characteristics, vanilla is ill-suited for large-scale plantations. The number of farms involved in vanilla production fluctuates between 50,000 and $100,000 .^{5}$

Table 2 provides descriptive statistics for vanilla farmers and for the EPM's average (more detailed descriptive statistics for the EPM's average can be found in the discussion paper version of the paper). Unfortunately, this is not a panel, so different households are included in each survey. ${ }^{6} \mathrm{Up}$ to 200 vanilla-growing households were included in each survey, which represents about $5 \%$ of the households surveyed. Comparing the characteristics of vanilla farmers in column 2 with the nationwide averages in column 1 suggests that they are quite close to the nationwide average. Two differences, however: a higher proportion of vanilla farmers are in the 'medium remoteness' category and, more importantly, vanilla farmer incomes are 15\% above the national average (even though the first 5-6 deciles among vanilla farmers are below the poverty line according to each survey). Also, compared with other agricultural activities, concentration in vanilla farming is less than the nationwide EPM average. Thus, in spite of the very low nationwide average income, higher producer prices received by vanilla farmers could contribute to widen rural inequality rather than reduce it.

${ }^{5}$ Data from Madagascar's EPMs suggest a figure about 90,000 with a substantial error margin because of imperfect stratification. A producer organisation quotes 70,000 farmers in 2004.

6 The variables used in this study were selected so as to be completely comparable across the four surveys. 
Table 1: Agricultural Population by Main Crop and Region, 1998

\begin{tabular}{|c|c|c|c|c|c|c|c|c|}
\hline \multirow[t]{2}{*}{ Crop/region } & \multicolumn{6}{|c|}{ Share in total number of producers $(\%)$, by crop } & \multirow{2}{*}{$\begin{array}{l}\text { Number of } \\
\text { producers }\end{array}$} & \multirow{2}{*}{$\begin{array}{l}\text { Share in } \\
\text { total }(\%)\end{array}$} \\
\hline & Antananarivo & Mahajanga & Fianarantsoa & Toamasina & Antsiranana & Toliary & & \\
\hline Rice & 22.4 & 11.1 & 26.7 & 18.3 & 12.9 & 8.7 & $2,804,244$ & 30.9 \\
\hline Other food crops & 40.4 & 7.0 & 14.9 & 13.4 & 5.8 & 18.5 & $4,402,227$ & 48.5 \\
\hline Sub-total food crops & 33.4 & 8.6 & 19.5 & 15.3 & 8.6 & 14.7 & $7,206,471$ & 79.5 \\
\hline Sugar cane & 7.3 & 18.0 & 32.5 & 21.3 & 10.6 & 10.2 & 422,267 & 4.7 \\
\hline Cotton & 0.0 & 25.0 & 0.0 & 8.2 & 4.1 & 62.7 & 20,783 & 0.2 \\
\hline Tobacco & 22.6 & 24.0 & 33.4 & 5.0 & 2.2 & 12.8 & 82,244 & 0.9 \\
\hline Peanuts & 27.0 & 8.7 & 30.4 & 5.9 & 2.0 & 26.1 & 575,794 & 6.3 \\
\hline Sub-total cash crops & 18.6 & 13.7 & 30.9 & 11.8 & 5.3 & 19.7 & $1,101,088$ & 12.1 \\
\hline Coffee & 1.2 & 3.2 & 41.2 & 32.8 & 19.9 & 1.6 & 480,897 & 5.3 \\
\hline Vanilla & 0.0 & 3.4 & 0.5 & 17.1 & 79.0 & 0.0 & 93,796 & 1.0 \\
\hline Pepper & 0.0 & 0.9 & 70.0 & 11.3 & 17.6 & 0.1 & 54,230 & 0.6 \\
\hline Cloves & 0.0 & 3.7 & 7.3 & 80.6 & 8.4 & 0.0 & 127,908 & 1.4 \\
\hline Cocoa & 0.0 & 1.2 & 0.0 & 3.9 & 94.9 & 0.0 & 5,883 & 0.1 \\
\hline Sub-total export crops & 0.8 & 3.1 & 32.2 & 37.1 & 25.6 & 1.0 & 762,714 & 8.4 \\
\hline Total & 28.9 & 8.7 & 22.0 & 16.7 & 9.6 & 14.1 & $9,070,273$ & 100 \\
\hline
\end{tabular}

Source: World Bank (2001). 
Table 2: Descriptive Statistics, Vanilla Farming: Household Surveys (Averages for 1993, 1997, 1999, 2001)

\begin{tabular}{|c|c|c|}
\hline & All, 1993-2001 & Vanilla \\
\hline Sample size & 9,504 & 578 \\
\hline Family size & 5.12 & 5.08 \\
\hline Number of communes & 450 & 34 \\
\hline \multicolumn{3}{|c|}{ Household head gender (proportion of households in category) } \\
\hline Male & 0.85 & 0.87 \\
\hline Female & 0.15 & 0.13 \\
\hline \multicolumn{3}{|c|}{ Household head education (proportion of households in category) } \\
\hline None & 0.31 & 0.25 \\
\hline Primary & 0.54 & 0.58 \\
\hline Secondary & 0.16 & 0.16 \\
\hline Cropland surface (ha) & 1.51 & 2.72 \\
\hline \multicolumn{3}{|c|}{ Land tenure (proportion of households in category) } \\
\hline Owned & 77.68 & 79.54 \\
\hline Sharecropping & 4.42 & 5.45 \\
\hline Rented & 3.82 & 3.30 \\
\hline \%Households outstanding loan & 4.18 & 1.75 \\
\hline \multicolumn{3}{|c|}{ Remoteness (proportion of households in category) } \\
\hline Low & 0.37 & 0.26 \\
\hline Medium & 0.43 & 0.57 \\
\hline High & 0.20 & 0.17 \\
\hline \multicolumn{3}{|l|}{ Yearly expenditure per capita } \\
\hline Thousand Malagasy Francs & 102.92 & 126.15 \\
\hline US dollars at PPP & 27.78 & 30.32 \\
\hline Share of livestock sales in cash income & 0.22 & 0.06 \\
\hline Share of crop sales in full income & 0.14 & 0.32 \\
\hline First-crop share in total harvest & 0.58 & 0.49 \\
\hline
\end{tabular}

Source: EPM, 1993-2001.

\section{Madagascar's Vanilla Policy: $1960-2003^{7}$}

This section summarises the three successive phases in Madagascar's vanilla policy since independence, the first two following a pattern common to much of SSA. Throughout the colonial period (not

7 Descriptions of Madagascar's vanilla policies are few. Apart from de Melo et al. (2000), which only covers the period up to 1990, to our knowledge, the only account is in Blarel \& Dolinsky (1995), which is dated and of difficult access. 
covered here), the vanilla market had been marred by price instability, low-farmgate prices and collusion among traders. Interestingly, the price volatility, trader concentration and hands-off government policy, which were the hallmarks of the colonial period-and prompted government intervention after independence-also characterise the current, post-reform regime. One essential difference, though, is that the contestability of the worldwide vanilla market has increased, making a swing of the pendulum back to interventionism unlikely.

\subsection{Phase 1 (1960-75)}

Right after independence, the Government of President Tsiranana intervened, setting up institutions with a twin objective: (i) correcting market failures and externalities in a bid to develop world demand for vanilla, and (ii) bring more stability and equity in the distribution of the gains from vanilla trade. ${ }^{8}$ A Vanilla Stabilization Fund (VSFCAVAGI under its French acronym) was created together with a licensing committee overseeing export trade. At all stages of the production process described earlier, prices were set by the authorities according to a cost-plus formula, the différentiel. Under this institutional set-up, the VSF was committed to buy all production at a pre-specified price and to stock it. Curers, packers and exporters had to obtain a licence to operate, and the date when the season for selling green vanilla was allowed to start was set by decree.

As described by Blarel \& Dolinsky (1995), the government's primary objective was to establish conditions for an orderly market that would continue to rely on the private sector, notably by setting up the regulatory foundations for an inter-professional vanilla organisation (GNIV). Nonetheless, from the start, the registration of packers-exporters was also intended to limit competition and entry, an objective that was surely favoured by established incumbents.

8 At the production stage, measures included the registration of vanilla growers, regulation of the marketing season for green vanilla to prevent harvesting before maturity and the branding process described above. At the curing stage, registration required compliance with minimum quality standardsessentially not to purchase immature vanilla beans. Packers-exporters also had obligations (purchase all vanilla beans on the market and store them with exports controlled by a quality department) which were overseen by a licensing committee. In the early years, the licensing committee which also oversaw the activities of the GNIV and the VSF was collegial, being composed of representatives from the private sector and the government. 


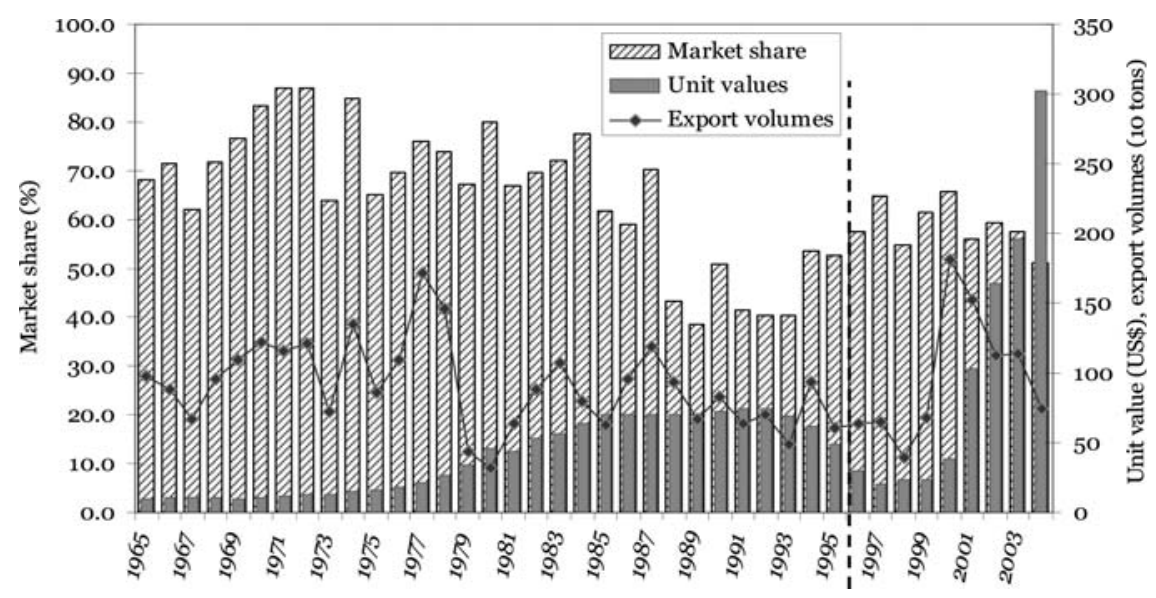

Figure 2: Madagascar's Vanilla Unit Values, Market Share and Export Volumes, 1965-2003. Source: Blarel \& Dolinsky (1995), COMTRADE (mirror statistics), authors' calculations

In 1962, an Indian Ocean cartel called the 'Vanilla Alliance' was formed with the Comoros and the Réunion. Its objective was to take advantage of the region's huge market power over the world's second most expensive spice, but also to correct externalities and bring the collective action necessary to develop the market by generic market promotion in the major consuming countries, and to insure quality. In the mid-1970s, the cartel's worldwide market share was above $80 \%$. Between CAVAGI and the 'Vanilla Alliance', vanilla was governed by a marketing board, hence our reference to the system as the VMB.

Figure 2 shows that government intervention was initially followed with positive results, with the world market expanding rapidly and Madagascar exports up by a factor of 5 in the 15 years following independence. It is also the phase when Madagascar established its lead in the market for vanilla. Blarel and Dolinsky (p. 295) conclude that this first phase was successful both on equity grounds, as the FOB price was about equally divided between growers, packers and the GOM/GAVAGI, and on efficiency grounds as the farmers' supply response was strong and quality maintained. 


\subsection{Phase 2 (1975-93)}

Starting in the mid-1970s, the Socialist revolution of President Didier Ratsiraka took the country into a State-led importsubstitution development strategy that rapidly threw the vanilla sector, like the rest of the economy, into disarray. Although the institutional set-up remained largely unchanged, policy became increasingly prone to rent-seeking, inefficiency and corruption.

Growers were required to hold three-year licenses and processorstockers annual ones, both granted by the Ministry of Trade, which also hand-picked small numbers among them (38 in 1989, 13 in 1990) for participation in the export trade. The Ministry also fixed the export quota allotted to each authorised processor-stocker. Again under the direction of the GOM, CAVAGI purchased the largest part of the crop to market it directly, fixing the price for all export transactions and those of the authorised exporters. Export quotas were allocated to politically favoured traders as were licences for curing and packing, resulting in a concentration of market power in the hands of a few. The tri-partite decision process involving growers, packers-stockers and the GOM which had been put in place after independence collapsed, as virtually all decisions were taken by the Ministry of Trade.

The replacement of the cooperative management system put in place under the previous government by centralised and politically motivated decisions led to increasingly distorted outcomes. Internally, export taxation became confiscatory, peaking at $82 \%$ of the pre-tax export price in the early 1990s (with the fraction of the export price received by farmers squeezed to less than $8 \%$ (Blarel and Dolinsky, 1995, p. 292). In spite of two exchange-rate corrections, in 1987 and in 1994, extortionary taxation was compounded, like in many other SSA countries, by currency overvaluation. Low producer prices discouraged plantation and maintaining quality. It also contributed-although on a limited scale because vanilla farmers were in small numbers-to the countryside's descent into poverty documented by Paternostro et al. (2001).

Externally, attempts to over-exploit monopoly rents led to the allocation of unused export quotas across exports from the Indian Ocean cartel. Even putting dynamic considerations aside, simulations suggest that CAVAGI's price was about twice the static welfaremaximising level, and a third above the revenue-maximising level 


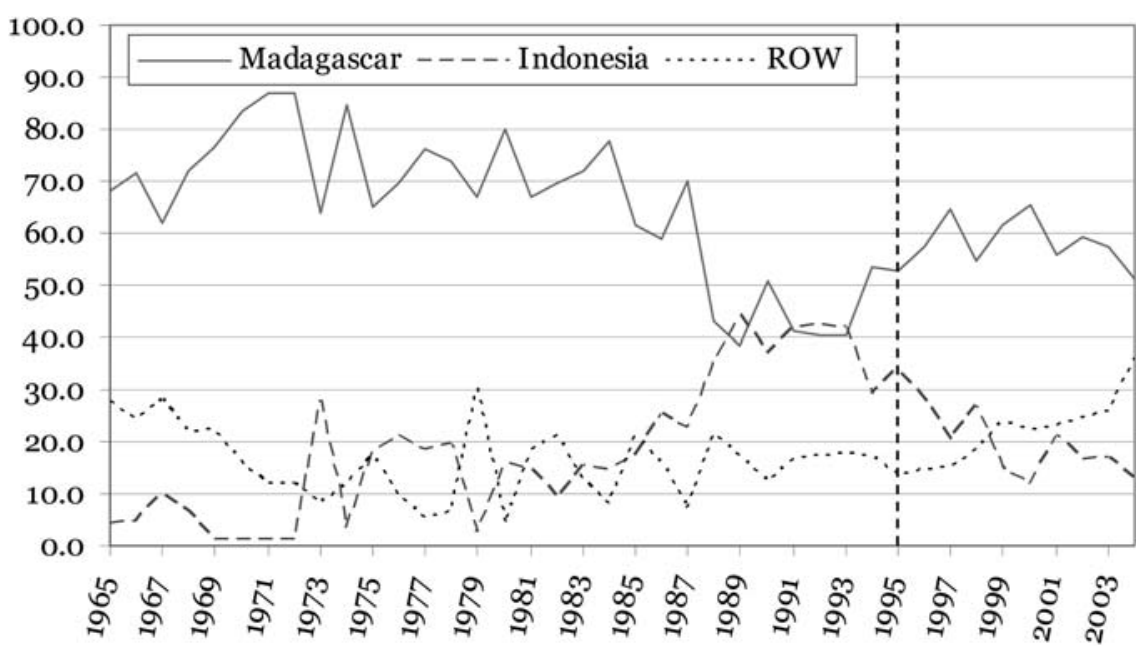

Figure 3: Market Shares on The World Vanilla Market, 1965-2003. Source: Blarel \& Dolinsky (2000), COMTRADE (mirror statistics), authors' calculations. Notes: ROW stands for world exports minus Madagascar and Indonesia

(de Melo et al., 2000), implying welfare losses adding up to about $1 \%$ of GDP. Illegal trade flourished while the cartel's high prices encouraged the entry of Indonesia into the market (Figure 3). ${ }^{9}$

Worst of all, declining revenues meant that the cost of keeping exploding inventories (as the cartel's high prices discouraged demand) escalated beyond what could be financed out of CAVAGI's revenue. In 1993, three quarters of the stock of inventories-which by 1990 exceeded four years' worth of export under good timeswere ultimately burnt. Given the then high unit value of vanilla (Figure 2), by any yardstick, the policies of the VSF were misguided and wasteful. ${ }^{10}$

${ }^{9}$ Indonesia's entry into the vanilla sector was driven by shortages in the late 1970s. The Government of Indonesia had no particular policy in that sector and has never taxed exports. It is estimated that Indonesia's costs of production are about three times those of Madagascar and that the surge in market share starting in the mid-1980s was induced by Madagascar's policies in phase 2 (see Blarel \& Dolinsky, 1995, and de Melo et al., 2000).

10 Examples of the corruption surrounding the operation of CAVAGI are described in Ecott (Chapter 13, especially pp. 220-223). This type of confiscatory policy extended beyond vanilla to other sectors (e.g., rice, clove etc.) and contributed to a trend of worsening rural poverty. 


\subsection{Phase 3 (1993-2005)}

The collapse of the GOM/CAVAGI system marked the beginnings of a new period of reforms in the sector, and the elimination of CAVAGI by Albert Zafy, who replaced Ratsiraka as president in 1993, coincided with other liberalisation measures in agriculture (Barrett, 1994) ${ }^{11}$ This third phase, which extends to the present, also saw the abolishment of the complexities in the licensing system and the removal of taxes on vanilla exports in 1995. Whether the government 'abandoned' the sector because rent-extraction was largely exhausted (see Bohman et al. 1996 for a discussion of this issue in the case of coffee in Indonesia), or because of the policy advice by donors (when Ratsiraka was re-elected in 1996 following the presidency of Albert Zafy, he was in a much weaker position and had to contend with advice by donors), the vanilla sector in Madagascar is no longer controlled as it was in phase 2, nor is there the kind of cooperation among interested parties that was once in place during phase 1 .

Under the new system, licences are still required of processors, but the system is a lot less constraining than it used to be, as it is easy to qualify for a licence. As shown in Figure 4, the elimination of CAVAGI and of export taxes was followed by a sharp reduction of the world price. Farmgate prices received by producers rose after 1995, before taking off starting in 1999 following fires in Indonesia and, later, cyclonic conditions in Madagascar in April 2000 (when one-fifth of the vanilla crop was destroyed). These exogenous events largely contributed to an overall shortage in the market for natural vanilla.

The State's role is now essentially confined to sanitary/quality inspections and to setting the date and place of vanilla marketing every year. ${ }^{12}$ Although this power alone has been shown elsewhere

11 Strictly speaking, CAVAGI was replaced by IVAMA, the Madagascar vanilla institute, with former CAVAGI as staff. Importantly, IVAMA did not have a monopoly on the amount that could be exported.

12 Arrêté interministériel 11672/2004 of 21 June 2004 (Agriculture and Trade Ministries of Malagasy Republic) prohibits the sales and exports of more than $100 \mathrm{~g}$ of vanilla less than six months after harvest. Annual ministerial decisions fix legal harvesting dates and stocking periods. In addition, the Sava region recently issued an Arrêté establishing minimum quality standards for vanilla, partly in response to the entry of fringe, low-quality producers during the highprice 2004 campaign. We are grateful to Sofia Bettencourt for pointing this out to us. Also see Ecott (p. 197) for a description of the different vanilla qualities. 


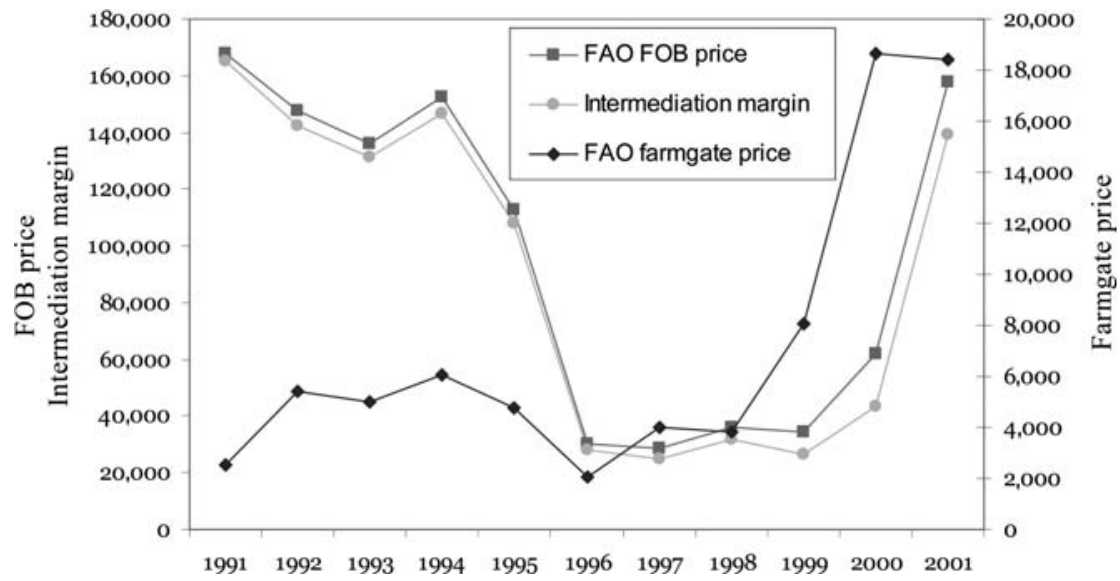

Figure 4: FAO Vanilla Farmgate and FOB Price, Deflated. Source: Table 4

to be a possible vehicle for extortion (e.g., Chad's cotton monopoly), with a weakened powers in Ratsiraka's presidency, the State's main role was to seek to discourage the marketing of non-mature vanilla (WTO, 2002). ${ }^{13}$ Efforts aimed at quality improvements are financed by the EU's Stabex fund in cooperation with the GES (Groupement des entrepreneurs de la SAVA) under a five-million euros project extending from 1997 to 2006.

However, 10 years after the market liberalisation, the market for high-quality 'bourbon' Malagasy vanilla is not at its best. The elimination of the marketing board was followed by a loss of cohesion between vanilla producers, collectors and exporters. Moreover, the escalation of producer prices from year 2000 until 2005 led to

13 The government's role has not changed under the new presidency. Government regulation of market opening dates is (at least in principle) necessary because Government regulation is called on to control this potential market failure. Whether Malagasy authorities succeed in their regulatory function is an open question, as Madagascar's vanilla market is less than fully transparent. According to a 2003 article published by Radio France International on the web, about a third of Madagascar's vanilla might be sold on the parallel market, some of which as part of money-laundering schemes (Péguy, 2003). Traders associations also complain that the prohibition of early collection makes harvests easy targets for organised crime. Large-scale thefts and armed ambushes of traders were reported in the local press during the high-price period of 2001-3. The situation was apparently serious enough to affect the harvest's pre-financing by foreign buyers. Ecott (Chapter 11) describes thefts and crimes related to conflicts between traders and growers. 


\section{Olivier Cadot et al.}

a rise of vanilla beans thefts together with a general increase of violence. Finally, vanilla quality slowly decreased, which, along with the huge price increase, encouraged world vanilla consumers in the food industry to partly turn away from natural vanilla to synthetic substitutes (see below).

We now turn to an assessment of the reforms, starting with a broad inspection of aggregate data before turning to micro evidence from the EPM and from simulation analysis.

\section{Assessing the Effect of Reforms}

Discerning the effects of the reforms described earlier is made difficult by several exogenous events: a major hurricane in April 2000 in Madagascar; a contested presidential election in late 2001 that brought the country to a standstill until July 2002 and large-scale fires in Indonesia in 1997 which destroyed a large chunk of the world's supply of natural vanilla. This said, three trends and a puzzle are apparent in Figures 2-4 since the reforms in 1993-95. First, recent years have been marked by a contraction of world exports (volumes contracted by about two-thirds, from 3,000 tons to little over 1,000 tons) matched by a spectacular rise in prices (Figures 2 and 4 ) and a huge decline in the intermediation margin following the elimination of CAVAGI in 1993 (note the different scales in Figure 4). Second, the decline in Madagascar's market share has reversed itself during the 1990s (Figure 3). Third, new entrants are progressively overtaking Indonesia as the main competition facing Madagascar (Figure 3). The puzzle is that the intermediation margin jumped again in 2001 (more on this below).

Interestingly, this development mirrors the early days of phase 2 when high prices triggered Indonesia's entry. Once again, in the wake of sharply rising prices (partly due to climatic conditions in Madagascar, where the cyclonic conditions in 2000 were followed by heavy rains in 2002), competition from new entrants-which together account for more than a third of world exports-is on the rise. ${ }^{14}$ Undeniably, the free market has certainly not stabilised the price, and it is said that the price hike of 2004 (which saw vanilla sold at $\$ 600$ per kilo) encouraged the food industry to

${ }^{14}$ Entrants include Costa Rica, India (whose output, at 120-130 tons, is equivalent to the Comoros's), Mexico and Papua-New Guinea (about 300 tons). Uganda is also reported to be raising output and quality (see e.g., www.cgiar.org/foodnet). 
substitute up to $30 \%$ of its purchases of natural vanilla with artificial vanillin (Ecott, 2004, p. 18).

Against this background, we now turn to the EPM surveys to try and detect evidence of the reforms on vanilla farmers. We start with an analysis of the evolution of intermediation margins, and then turn to parametric estimates of supply response before looking at the evolution of regional indices of inequality and poverty.

\subsection{Evidence from Household Surveys}

We start with prices, intermediation margins and supply response, and then turn to regional inequality and poverty. The elimination of the VMB corresponds to the replacement of a state-owned monopoly by a market structure for intermediaries that can be expected to be fairly concentrated at the outset but to become more competitive over time as entry is attracted by high intermediation margins. Thus, except under very peculiar settings, one should expect intermediation margins to narrow down over time, especially given that, as mentioned above, CAVAGI's margins appeared to be vastly in excess of even a rational monopoly's optimal level.

\subsubsection{Intermediation, Margins and Supply Response}

Table 3 gives the evolution of vanilla prices from different sources: EPM surveys, FAO data, GOM and COMTRADE data. There is a large discrepancy in the series even though the farmgate prices show the same increasing trend across the series: according to the EPM survey, farmgate prices increase over eightfold in real terms over the period 1993-2001 while the corresponding increase in the FAO series is less than fourfold, and the government figures are flat over the available period (1993-97). In general, the FAO and COMTRADE CIF series (based on mirror importer statistics deemed to be more reliable) are quite close as can be seen from comparing the last two columns. ${ }^{15}$

15 Note however that the FAO FOB prices are higher than the COMTRADE CIF prices between 1996 and 2001. Note however that FAO farmgate prices are in all likelihood prices quoted by established traders. It is possible, though unverified, that parallel exports were purchased from farmers at higher prices. Furthermore, there are discrepancies between FOB and CIF series in COMTRADE data (see the discussion in Hummels \& Lugovsky, 2006). 
Table 3: Farmgate, FOB and CIF Vanilla Prices, 1991-2001

\begin{tabular}{|c|c|c|c|c|c|c|c|c|}
\hline \multirow[t]{3}{*}{ Year } & \multicolumn{2}{|c|}{$\begin{array}{l}\text { EPM average pro- } \\
\text { ducer price }\end{array}$} & \multicolumn{2}{|c|}{$\begin{array}{l}\text { Government } \\
\text { farmgate price, } \\
\text { FMG }\end{array}$} & \multicolumn{2}{|c|}{$\begin{array}{l}\text { FAO farmgate } \\
\text { price, FMG }\end{array}$} & \multirow{3}{*}{$\begin{array}{l}\text { Percentage of FAO FOB } \\
\text { market price received by } \\
\text { producers } \\
4\end{array}$} & \multirow{3}{*}{$\begin{array}{l}\text { Percentage of COMTRADE } \\
\text { CIF market price received } \\
\text { by producers } \\
5\end{array}$} \\
\hline & \multicolumn{2}{|l|}{1} & \multicolumn{2}{|l|}{2} & \multicolumn{2}{|l|}{3} & & \\
\hline & Current & Constant & Current & Constant & Current & Constant & & \\
\hline 1991 & & & & & 2,000 & 2,526 & 1.51 & 1.47 \\
\hline 1992 & & & & & 5,000 & 5,416 & 3.67 & 3.81 \\
\hline 1993 & 4,062 & 4,062 & 2,875 & 2,875 & 5,000 & 5,000 & 3.67 & 3.83 \\
\hline 1994 & & & 4,500 & 3,217 & 8,450 & 6,040 & 3.96 & 4.54 \\
\hline 1995 & & & 7,550 & 3,583 & 10,000 & 4,746 & 4.22 & 4.75 \\
\hline 1996 & & & 5,750 & 2,293 & 5,150 & 2,053 & 6.85 & 4.15 \\
\hline 1997 & 17,788 & 6,813 & 7,500 & 2,873 & 10,500 & 4,022 & 14.04 & 10.37 \\
\hline 1998 & & & 10,500 & 3,794 & 10,500 & 3,794 & 10.60 & 8.28 \\
\hline 1999 & 21,950 & 7,068 & & & 25,000 & 8,050 & 23.44 & 17.55 \\
\hline 2000 & & & & & 66,250 & 18,673 & 30.13 & 26.05 \\
\hline 2001 & 133,559 & 35,202 & & & 69,828 & 18,404 & 11.67 & 11.48 \\
\hline
\end{tabular}

Source: FAO, COMTRADE, EPM, MAEP. 
Whatever price information is used, Table 3 gives support to a shortage-induced price hike mentioned above, but also more importantly it provides evidence of a reduction in intermediation margins. First, world prices went up sharply between 1999 and 2001, from FMG 200,000 to 600,000 per kilogram. According to various press and professional sources, prices continued to climb until 2004, reaching close to US $\$ 150 / \mathrm{kg}$, only to collapse abruptly in the fall of 2004, settling at US $\$ 60 / \mathrm{kg}$ (FMG 600,000 at the 2004 exchange rate). Prices were also oriented downwards in 2005. The high prices of 2001-3, partly due to the fact that hurricane 'Hudah' in April 2000 wiped out about a third of the region's output and $15 \%$ of its stocks, ${ }^{16}$ are widely reported to have encouraged the entry of informal traders in the market, with consequent loss of control by established traders and government authorities.

Second, as expected, the elimination of CAVAGI in 1993 immediately translated into a sharp increase in the fraction of vanilla FOB prices retained by producers, from a low of less than $2 \%$ in 1991 to a high of 30\% in 2000 (Figure 4). However, Figure 4 reveals that the squeeze in intermediation margins abruptly reversed itself in 2001, a year in which none of the sharp increase in export prices was retained by producers whose farmgate prices stayed flat, at least according to the FAO data. This puzzling change noted earlier is however partly elucidated when one looks at columns 4 and 5 in Table 3, which indicate unusually high producer prices in 1999 and 2000 while the margins in 2001 correspond to those that had established around 1998 after the removal of the VMB. ${ }^{17}$

Figure 5 shows hectares planted, yields and vanilla output over a 20-year period straddling CAVAGI's elimination. As is obvious from the figure, there is little prima facie evidence of a strong

16 See www.vanilla.com. Hurricane damage on production capacity persists for about three years, the plant's maturing period. The wet season in 2002 also accounted for a poor harvest whose effects on supply were felt two years later in 2004.

17 The $2 \%$ figure for 1991 is probably an underestimate. Blarel \& Dolinsky (1995, p. 292) quote a figure of $8 \%$ but suggest that this number is itself an upper bound, so the truth is likely to be somewhere between 2 and $8 \%$. In any case, both FAO or GOM prices series yield very similar estimates of reductions in intermediation margins. As to the reasons for the abrupt changes in 1999 and 2000, one could appeal to the exogenous climatic factors in Madagascar and Indonesia. 
408 Olivier Cadot et al.

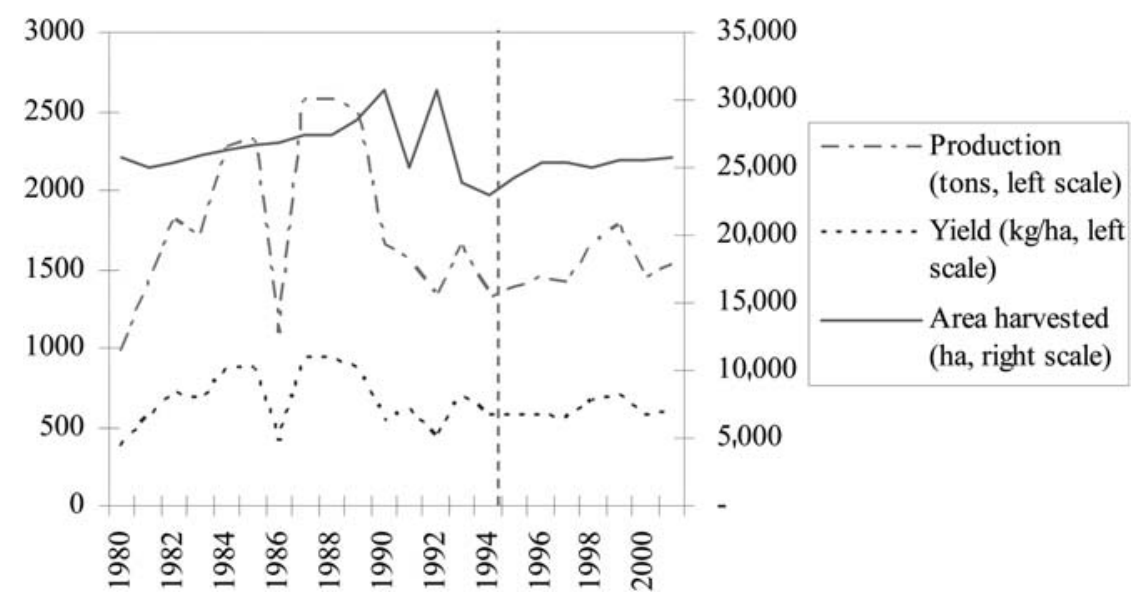

Figure 5: Vanilla Areas Planted, Yield and Output, 1980-2001. Source: FAO stat

supply response to the reduction in intermediation margins over 1995-2001. This is not surprising given the unstable climatic conditions in 2000, the three-year delay between plantation and harvest time and the unrest surrounding the presidential elections of 2001. This is somewhat confirmed by a report on the Sava region ('Monographie de la région de la Sava', GOM, 2003), which states that the increase in vanilla-planted area following the elimination of the marketing board corresponds to a better care given to vanilla sprouts and to the renewal of old sprouts rather than to a physical increase in plantation. However, according to local sources, an increase in planted areas in the Sava region did take place in 2004, and the parametric estimates below also suggest some supply response. Overall, the data in Figure 5 suggest that the improvement in Madagascar's market share observable in Figure 3 is likely to reflect more the slackening of the competitive pressure from Indonesia than a positive domestic supply response to the improved price signals received by Malagasy vanilla farmers.

To check further on farmers' behaviour, we now turn to a parametric analysis. Farmers' decisions to grow vanilla or not are likely to be related to how much they would grow if they decided to go ahead; pretty much like, the decision to participate in the labour force is related to how many hours one would 
supply if participating. ${ }^{18}$ Accordingly we fit a two-stage Heckman model (equation (1)) with a production equation (whose dependent variable is vanilla output) and a participation equation (whose dependent variable is 1 for farmers who grow any vanilla and 0 for others). The selection equation is identified using location and community characteristics. We estimate the following two-stage selection model over approximately 500 vanilla farmers for each one of two household surveys (1997 and 1999):

$$
\begin{aligned}
& y_{i t}=X_{i t} \beta+u_{i t}, \\
& I_{i t}^{*}=Z_{i t} \gamma+v_{i t}, \\
& I_{i t}=\left\{\begin{array}{ll}
1 & \text { if } I_{i t}^{*}>0 \\
0 & \text { otherwise }
\end{array},\right. \\
& i=1, \ldots, n \\
& t=1, \ldots, 2,
\end{aligned}
$$

where $y_{i t}$ is the $\log$ of farm $i$ 's vanilla output in survey $t, I_{i t}$ is equal to one when farm $i$ grows vanilla in survey year $t$ and $I_{i t}^{*}$ represents the net benefit of growing vanilla and is latent. $X$ is a vector of household characteristics likely to influence a farmer's portfolio choice and productivity, whereas $Z$ is a vector of household and community characteristics-including location-likely to influence a farmer's decision or ability to grow vanilla at all.

We are mainly interested in the relationship between participation decisions and vanilla prices, but with a cross-section there is no variability in prices (who are the same for all farmers) except for changes across surveys (i.e., up to four values if we included all surveys). Accordingly, we construct a farmer-specific index of the past change in the price of long-term crops using FAO price series for the last 10 years and current production weights. A positive coefficient in front of this variable in the selection equation indicates that, ceteris paribus, a past increase in the price of long-term crops makes it more likely for a farmer to

${ }^{18}$ Technically, omitted variables such as a farmer's ability or equipment may influence both his decision to grow vanilla and how much to grow, which implies $\operatorname{cov}\left(u_{i t}, v_{i t}\right) \neq 0$, see equations below. 
grow vanilla if that farmer already had a large share of long-term crops, i.e., if his land was suitable.

However, as explained by Paternostro et al. (2001), comparability across household surveys is quite limited. As they explain, the 1993 survey was a year-long survey, while the 1997 and 1999 surveys were the three month priority surveys. These surveys come close to a panel since approximately $60 \%$ of the households in the 1999 survey had been part of the 1997 survey (p. 73). As to the 2001 survey, not only was there a change in the coverage of goods entering the consumption basket, with more goods consumed by the poor, but there was also a change in the sampling methodology, as the proportion of urban households sampled increased (Romani, 2003). Given the discrepancies between the 1999 and 2001 surveys, except when noted explicitly, in the results below we confine ourselves to the 1997 and 1999 surveys. Admittedly, because of data limitations, with only two surveys, this is a very indirect test of the supply response to price changes. Accordingly, results should be interpreted very cautiously.

The definition of the variables are in Table 4 and results are shown in Table 5. Regarding the choice of community characteristics entering the selection equation, because of their large number, we relied on a systematic search. ${ }^{19}$ As to the appropriateness of Heckman's model, the null hypothesis of independence of the two equations (selection and production) is rejected at the $1 \%$ level, so a probit on the selection equation would produce inconsistent estimates.

Starting with the selection equation, farm size is a highly significant determinant of farmers' choice to grow vanilla, suggesting that vanilla production is a sort of luxury for farms with enough land to grow other (food) crops. In accordance with the description of vanilla farming, input and fertiliser use enter negatively in the decision to grow vanilla. Most of the other community characteristics also enter with plausible signs, all suggesting that vanilla is mostly grown by isolated and precarious farmers in unsafe areas. However, the positive and significant sign on total revenue suggests that vanilla farmers are the 'rich' among the very poor, which is not surprising considering that vanilla is an export crop

19 We relied on the systematic selection procedure used by Sala-i-Martin (1997). We did not apply this procedure to the output equation because only a few variables in the household surveys were likely to affect supply. 
Table 4: Description of Variables

Cropland size

\section{Owner \\ Tenant \\ Sharecropper \\ Inputs}

Fertiliser use

Outstanding loan

Rain

Disturbances

Frequency of droughts

Frequency of locust attacks

Frequency of epizootic disease

Travel time to the next town

Population in the village

Share of agricultural population

Farmers association

Agricultural extension service

Community cattle

Number of break-in
Number of squared metres of land the household crops or has in fallow, in logs

Proportion of owned cropped land

Proportion of rented cropped land

Proportion of cropped land in sharecropping

Dummy indicating whether the household used inputs in its production; $1=$ yes, $0=$ no

Share of the farmers of the community who use fertilisers. $0=0 \%, 1 \leq 5 \%, 2=5-25 \%$, $5 \geq 75 \%$

Dummy indicating whether the household has a loan meant for agriculture; $1=$ yes, $0=$ no

Quantity of rain in the last year

Index indicating the risk of atmospheric disturbances. Goes from $0=$ low risk to $5=$ high risk

Number of years with droughts between 1999 and 2001

Number of years with locust attacks between 1999 and 2001

Number of years with epizootic disease between 1999 and 2001

Number of hours of travelling to reach the next town

Number of persons in the village

Share of the population of the community in the agricultural sector

Farmers association dummy indicating whether the village where the household lives has an association of farmers; $1=$ yes, $0=$ no

Dummy indicating if the village could benefit from agricultural extension service; $1=$ yes, $2=$ no

Size of the cattle in the village

Number of break-in in the village between 1999 and 2001 


\section{Olivier Cadot et al.}

Table 4: Continued

Presence of police

Presence of police in the village; $1=$ yes, $0=$ no

Independency ratio

Number of working persons in the household over household size

Average age in household

Household members' average age

Household head schooling

Household head's last achieved school year. 1-6: primary school; 7-13: secondary school; 14-18: university

Total revenue

Household's total revenue

Price index for long-term crops

Price index for long-term crops, in logs

Price index for short-term crops

Price index for short-term crops, in logs

while most farmers grow food crops for self-consumption. Finally, the positive coefficient on long-term ${ }^{20}$ crops' $^{\prime}$ past price changes (a weighted average of their price changes over the past 10 years using current weights in farm production) suggests a positive supply response through entry, although, as mentioned, this must be interpreted cautiously.

Logically, the supply equation indicates that inputs and fertiliser use increase supply (even if they do not affect the planting decision). Somewhat surprisingly, the 1999 dummy enters with a negative sign, suggesting a lower output compared than for 1997. Given that adverse climatic conditions occurred in 2000, this is somewhat surprising since producer price was rising and adverse weather conditions occurred in the Spring 2000. However, when we ran a similar regression (not reported here) including all four surveys including year dummies (except for 1993) in the supply equation, as expected the dummy variables for 1997 and 1999 were positive and significant and the dummy variable for 2001 was negative. It is thus difficult to detect output effects of the abolishment of CAVAGI.

\subsubsection{Regional Inequality and Poverty}

At less than 100,000 (1\% of the total), the number of vanilla farmers is too small for vanilla policy to affect nationwide measures of

${ }^{20}$ Long-term crops are defined as crops that need more than 1.5 years to reach maturity. 
Table 5: Estimation Results, Vanilla Farming Regression: 1997 and 1999¹

Dependent variable

Vanilla $=1$ (selection) $\quad$ Ln vanilla output $(\mathrm{kg})$

\begin{tabular}{|c|c|c|}
\hline Cropland size & $0.28^{* * *}(4.29)$ & $0.08(0.96)$ \\
\hline Owner & $-0.34^{* *}(2.02)$ & $-0.06(0.28)$ \\
\hline Sharecropper & $-0.56^{*}(1.93)$ & $-0.07(0.18)$ \\
\hline Tenant $^{2}$ & $-0.70^{* *}(2.36)$ & $0.65^{* *}(2.42)$ \\
\hline Inputs (cap. equipment) & $-0.71^{* * *}(3.56)$ & $0.50^{* *}(2.28)$ \\
\hline Fertiliser use & $-0.35^{* * *}(4.85)$ & $0.07^{* *}(1.98)$ \\
\hline Outstanding loan & $-0.03(0.08)$ & $-0.15(0.33)$ \\
\hline 1999 & $-0.62^{* * *}(6.83)$ & $-0.38^{* * *}(3.63)$ \\
\hline Rain & $-5.59 \mathrm{E}-04^{* * *}(7.67)$ & \\
\hline Disturbances & $-0.93^{* * *}(7.56)$ & \\
\hline Frequency of droughts & $-0.54^{* * *}(7.29)$ & \\
\hline Frequency of locust attacks & $-0.11(1.13)$ & \\
\hline $\begin{array}{l}\text { Frequency of epizootic } \\
\text { disease }\end{array}$ & $-0.05^{* * *}(2.92)$ & \\
\hline Travel time to the next town & $0.02^{* * *}(5.45)$ & \\
\hline Population in the village & $-3.97 \mathrm{E}-05^{* * *}(5.36)$ & \\
\hline $\begin{array}{l}\text { Share of agricultural } \\
\text { population }\end{array}$ & $0.02^{* * *}(2.73)$ & \\
\hline Farmers association & $0.77^{* * *}(6.48)$ & \\
\hline $\begin{array}{l}\text { Agricultural extension } \\
\text { service }\end{array}$ & $1.62^{* * *}(6.51)$ & \\
\hline Community cattle & $-9.61 \mathrm{E}-05^{* * *}(4.16)$ & \\
\hline Number of break-in & $0.02^{* * *}(11.49)$ & \\
\hline Presence of police & $-1.07^{* * *}(9.03)$ & \\
\hline Independency ratio & $-0.55^{* * *}(3.14)$ & \\
\hline Average age in household & $-6.40 \mathrm{E}-04(0.17)$ & \\
\hline Household head schooling & $0.02 *(1.80)$ & \\
\hline Total revenue & $2.83 \mathrm{E}-07^{* * *}(4.76)$ & \\
\hline $\begin{array}{l}\text { Price index for long-term } \\
\text { crops }^{3}\end{array}$ & $12.19^{* * *}(25.22)$ & \\
\hline $\begin{array}{l}\text { Price index for short-term } \\
\text { crops }^{4}\end{array}$ & $-1.19^{* * *}(3.32)$ & \\
\hline Constant & $-1.07(1.49)$ & $3.54^{* * *}(4.38)$ \\
\hline Observations & 1464 & 1464 \\
\hline$F(8,1454)$ & 3.61 & \\
\hline Probability $>F$ & 0 & \\
\hline
\end{tabular}




\section{Olivier Cadot et al.}

Table 5: Continued

\begin{tabular}{|c|c|c|}
\hline Dependent variable & Vanilla = 1 (selection) & Ln vanilla output (kg) \\
\hline$\rho^{5}$ & $-0.96^{* * *}(-64.51)$ & \\
\hline$\sigma^{6}$ & $1.08^{* * *}(25.24)$ & \\
\hline
\end{tabular}

t-Statistics in brackets.

${ }^{1}$ Regression for vanilla region only.

${ }^{2}$ Omitted category: landless farmers tilling community land.

${ }^{3}$ Preceding 10-year change in output-weighted Laspeyres price index.

${ }^{4}$ Preceding three-year standard deviation in output-weighted Laspeyres price index.

${ }^{5}$ Coefficient of correlation between the two equations.

${ }^{6}$ Variance of error terms in vanilla output regression.

*Significant at $10 \%$; ** significant at $5 \%$; ${ }^{* * *}$ significant at $1 \%$.

inequality and poverty. However, the importance of vanilla for the Malagasy economy is still very large: vanilla constitutes a major source of Malagasy exports revenue. Besides, revenues from the vanilla sector represent $1.5 \%$ of Malagasy GDP. ${ }^{21}$ As vanilla farming is concentrated in just two provinces (Antsiranana and, to a much lesser extent, Toamasina), it makes sense to explore the evolution of inequality and poverty indices for those regions in order to track any possible aggregate effect of the 1995 change in Madagascar's vanilla policy. However, in order to control for other changes that could have affected nationwide inequality and poverty levels, we compare the vanilla regions with the other four regions in Madagascar where vanilla is not produced. ${ }^{22}$ Furthermore, because the EPM surveys are strictly not comparable, it is useful to compare the vanilla and non-vanilla regions within each survey as well as the evolution in time.

Tables 6 and 7 show the evolution of poverty and inequality measures across the four EPM surveys (ignore for now the counterfactual column figures in table 6 giving the simulated numbers for

21 'Etat des lieux de la corruption sur l'économie rurale', 2003.

22 Note that since our database includes households with agriculture as one of their activities only, the poverty estimates given in this section are not done on the whole population. However, since farmers represent about $90 \%$ of the Malagasy population, our estimates themselves represent most of the population. 
Table 6: Poverty Headcount, Poverty Gap and Gini Indices (Vanilla Regions)

\begin{tabular}{|c|c|c|c|c|c|c|c|c|}
\hline & \multicolumn{2}{|c|}{ Headcount } & \multicolumn{2}{|c|}{ Headcount ratio } & \multicolumn{2}{|c|}{ Poverty gap ratio } & \multicolumn{2}{|c|}{ Gini coefficient } \\
\hline & Actual & Counterfactual & Actual & Counterfactual & Actual & Counterfactual & Actual & Counterfactual \\
\hline 93 & 386,808 & NA & 0.841 & NA & 0.491 & NA & 0.427 & NA \\
\hline 97 & 353,473 & NA & 0.759 & NA & 0.349 & NA & 0.366 & NA \\
\hline 99 & 339,783 & NA & 0.723 & NA & 0.333 & NA & 0.390 & NA \\
\hline 01 & 324,316 & 346,570 & 0.782 & 0.836 & 0.394 & 0.440 & 0.418 & 0.418 \\
\hline
\end{tabular}


Table 7: Poverty Headcount, Poverty Gap and Gini Indices (Non-vanilla Regions)

Headcount Headcount ratio Poverty gap ratio Gini coefficient

$\begin{array}{lllll}93 & 1,055,480 & 0.860 & 0.512 & 0.477 \\ 97 & 865,358 & 0.744 & 0.346 & 0.377 \\ 99 & 874,391 & 0.748 & 0.349 & 0.384 \\ 01 & 937,759 & 0.813 & 0.450 & 0.421\end{array}$

Source: Authors' calculations from EPM. Poverty line defined as in Paternostro (1999), i.e., budgetary requirements to purchase 2,100 calories a day at current prices.

Headcount: number of individuals below poverty line; headcount number: proportion of individuals (using EPM's survey design) in poverty; poverty gap ratio: average (poverty line-revenue)/poverty line;

counterfactual: counterfactual values obtained from baseline scenario $\left(\varepsilon_{\mathrm{v}}=1.0\right.$, $\left.\varepsilon_{\mathrm{s}}=0.5, \sigma=4\right)$. See Appendix A for the description of model and Table A1 for sensitivity results to changes in assumptions about elasticities.

2001). Between 1993 and 1999, the period straddling the reforms, the headcount went down more rapidly in the non-vanilla regions (11.6 versus 8.2 percentage points). ${ }^{23} \mathrm{~A}$ similar catching up of the non-vanilla region is also evident from the poverty gap and Gini figures over the same period. However, between 1997 and 1999 when vanilla prices were going up, poverty continued to fall in the vanilla region but inequality went up. This should not be surprising since periods of strong growth are known to result in increases in inequality under a wide range of density functions. By contrast, there is no improvement on the poverty front in the non-vanilla regions and only a slight increase in inequality.

For both regions, poverty and inequality went up between 1999 and 2001. This trend seems plausible for the non-vanilla region as the long-term decline in agriculture continued (with the better-off farmers leaving the countryside for cities), but is surprising and suspicious for the vanilla region when one inspects the data by deciles in Table 8.

23 The 1993 figures seem however to be overestimated: both poverty headcount and poverty gap ratio are higher compared with Paternostro et al.'s figures. Our $10 \%$ figure of people out of poverty might therefore in turn be underestimated. 


\begin{tabular}{|c|c|c|c|c|c|c|c|c|c|c|}
\hline \multirow[t]{2}{*}{ Decile $^{1}$} & \multicolumn{2}{|c|}{ Per-capita income ${ }^{2}$} & \multicolumn{2}{|c|}{$\begin{array}{l}\% \text { Income from } \\
\text { vanilla sales in total } \\
\text { income }^{3}\end{array}$} & \multicolumn{2}{|c|}{$\begin{array}{l}\% \text { Income from non- } \\
\text { vanilla sales in total } \\
\text { income }^{4}\end{array}$} & \multicolumn{2}{|c|}{$\begin{array}{l}\text { Wage change } \\
1999-2001^{5}\end{array}$} & \multicolumn{2}{|c|}{$\begin{array}{l}\text { Producer price } \\
\text { change } 1999-2001^{6}\end{array}$} \\
\hline & $\begin{array}{l}\text { Vanilla } \\
\text { regions }\end{array}$ & $\begin{array}{l}\text { Non-vanilla } \\
\text { regions }\end{array}$ & $\begin{array}{l}\text { Vanilla } \\
\text { regions }\end{array}$ & $\begin{array}{l}\text { Non-vanilla } \\
\text { regions }\end{array}$ & $\begin{array}{l}\text { Vanilla } \\
\text { regions }\end{array}$ & $\begin{array}{l}\text { Non-vanilla } \\
\text { regions }\end{array}$ & $\begin{array}{l}\text { Vanilla } \\
\text { regions }\end{array}$ & $\begin{array}{l}\text { Non-vanilla } \\
\text { regions }\end{array}$ & $\begin{array}{l}\text { Vanilla } \\
\text { regions }\end{array}$ & $\begin{array}{l}\text { Non-vanilla } \\
\text { regions }\end{array}$ \\
\hline 1 & 50,034 & 44,596 & 13.8 & 0 & 39.4 & 37.7 & 3.31 & 0.31 & -0.50 & -0.60 \\
\hline 2 & 76,673 & 72,304 & 9.8 & 0 & 33.0 & 42.7 & 4.15 & 1.07 & 3.67 & 0.03 \\
\hline 3 & 96,165 & 89,165 & 17.8 & 0 & 24.4 & 31.5 & 2.27 & 1.18 & 0.27 & 0.11 \\
\hline 4 & 118,190 & 110,145 & 13.3 & 0 & 34.4 & 33.6 & 2.06 & 0.88 & 0.69 & -0.01 \\
\hline 5 & 140,270 & 130,377 & 11.8 & 0 & 22.0 & 35.9 & 0.72 & 1.46 & 0.84 & -0.17 \\
\hline 6 & 166,974 & 155,203 & 9.7 & 0 & 26.3 & 34.7 & 3.42 & 1.52 & -0.18 & 0.10 \\
\hline 7 & 195,187 & 189,817 & 12.3 & 0 & 29.5 & 34.3 & 2.31 & 1.08 & 1.08 & -0.04 \\
\hline 8 & 241,774 & 230,948 & 11.0 & 0 & 26.5 & 28.1 & 1.47 & 1.14 & 0.26 & -1.24 \\
\hline 9 & 325,682 & 305,814 & 13.3 & 0 & 17.9 & 25.8 & 1.86 & 0.68 & 1.13 & -0.24 \\
\hline 10 & 599,147 & 534,520 & 9.4 & 0 & 27.2 & 30.3 & 1.53 & 0.78 & -0.04 & -0.19 \\
\hline
\end{tabular}

${ }^{1}$ Ranked from poorest to richest.

${ }^{2}$ Decile's average per-capita income (included estimated value of auto-consumption) in real (CPI-deflated) FMG, 1999.

${ }^{3}$ Decile's average percentage of income from vanilla sales in total income, 1999.

${ }^{4}$ Decile's average percentage of income from crop sales other than vanilla in total income, 1999.

${ }^{5}$ 1999-2001 real wage change was calculated for pseudo-panels defined by the narrowest geographical areas (i.e., villages) for which we had observations in both years.

${ }^{6}$ Calculated as the decile's average of the individual weighted-producer price change, itself calculated as $\Delta p_{i j}=\sum_{j} w_{i j}^{P} \Delta p_{j}^{P}$, where $i$ indexes households in the decile, $j$ indexes crops and $w_{i j}^{P}$ is the weight of crop $j$ in household $i$ 's income. Change in vanilla prices is not included. 


\section{Olivier Cadot et al.}

According to Table 8, vanilla revenues account for a bit more than $10 \%$ of revenues, with no trend across deciles, while revenues from sales of other crops accounts for another 30\% of household revenue, with a slight decline in the share for higher deciles. So, except for the lowest deciles, crop sales account for less than half of household income, an estimate quite close to the one for household in non-vanilla-growing regions. The low share of cash income in total income in Malagasy households reflects the subsistence living conditions of the poor in rural areas. While these descriptive statistics (from the 1999 survey) could account for the deterioration between the 1999 and 2001 EPM surveys, our estimate of wage changes between the 1999 and 2001 EPM indicates a much larger increase in the vanilla region, the increase being steeper for the lower deciles. Finally, the changes in producer prices are more favourable for the vanilla regions, with the increase in the vanilla regions suggesting some spillovers from vanilla to other activities, while the decline elsewhere mirrors the continuing decline of Malagasy agriculture recounted by several observers. Together, these results cast some doubts that, even if one factors in the effects of cyclonic conditions and the large share of autoconsumption for poor households, poverty and inequality indicators may not have deteriorated as much as suggested by the indicators in Tables 6 and 7 for the vanilla-growing regions.

Inspection of the household data does not reveal clear-cut changes in inequality and poverty indices in the vanilla-growing regions, nor is there strong evidence of supply response from the household data. However, the price data suggest a marked decline in intermediation margins which we exploit below in a simulation-based counterfactual re-creating the old policy environment to try and give an answer to the question: how much did the reforms achieve by themselves?

\subsection{A Simple Counterfactual}

Drawing on the econometric supply and demand estimates in de Melo et al. (2000), let the vanilla market be approximated by modelling three types of players: a supply side with atomistic producers (farmers); a demand side black-boxed with a constant price-elasticity of demand for aggregate (Madagascar and Indonesia) natural vanilla; and a layer of imperfectly competitive 
curers-stockers-traders engaged in Cournot competition in the middle. ${ }^{24}$ In this set-up, reminiscent of the vanilla market in Madagascar, the taxation of exports followed during phase 2 leads to an outcome akin to double marginalisation (this is clear from the model description in Appendix A).

The gist of the model boils down to a simple formula relating the share of the world price retained by Madagascar's producers as a function of demand and supply elasticities and, more importantly, the number of local traders. Namely, letting $P_{\mathrm{M}}$ be the selling price of Madagascar's vanilla (whose formula is derived in Appendix A), $p_{\mathrm{M}}^{P}$ its farmgate producer price, $\sigma$ the elasticity of substitution between Madagascar's and Indonesia's vanilla, $s_{M}$ Madagascar's market share and $\varepsilon_{\mathrm{M}}^{s}$ the elasticity of supply of Madagascar's vanilla, the inverse of the intermediation margin, $\theta_{\mathrm{M}}$, is given by:

$$
\theta_{\mathrm{M}}=\frac{p_{\mathrm{M}}^{P}}{P_{\mathrm{M}}}=\frac{1-\left\{(1 / \sigma)+[1-(1 / \sigma)] s_{\mathrm{M}}\right\}}{1+\left[1 /\left(n_{M} \varepsilon_{M}^{s}\right)\right]} .
$$

It is easily checked that $\theta_{\mathrm{M}}$, the share of the price accruing to farmers, is increasing in the elasticity of supply and in the number of traders, as raising either of those parameters reduces their monopsonistic power.

Starting from observed mark-ups, we let the model determine the number of traders consistent with the imposed behaviour under the current policy regime of no taxation and no domestic market intervention restricting entry. As indicated in Table A1 in Appendix A, these model-generated numbers are close to the anecdotal evidence (about five traders, which happens to be the number of packers that, according to Blarel \& Dolinsky (1995, p. 274), dominates the vanilla intermediation business). Taken at face value, this suggests that there was little entry since the mid-1990s or that, if there was, new entrants followed the incumbents' pricing policy. ${ }^{25}$

24 This set-up is the same as de Melo et al.'s (2000) except for the addition of the layer of imperfectly competitive curers-stockers-traders and the Cournot (rather than Stackelberg) assumption describing the interaction between Madagascar and Indonesia.

25 Our counterfactual experiment reduces the number of traders to one, based on the assumption that they colluded during the socialist era. With export quotas, they obviously had little incentive to compete on prices. Indeed, Blarel \& Dolinky (1995) describe a process through which the political allocation of export licences increasingly concentrated power in the hands of a single 


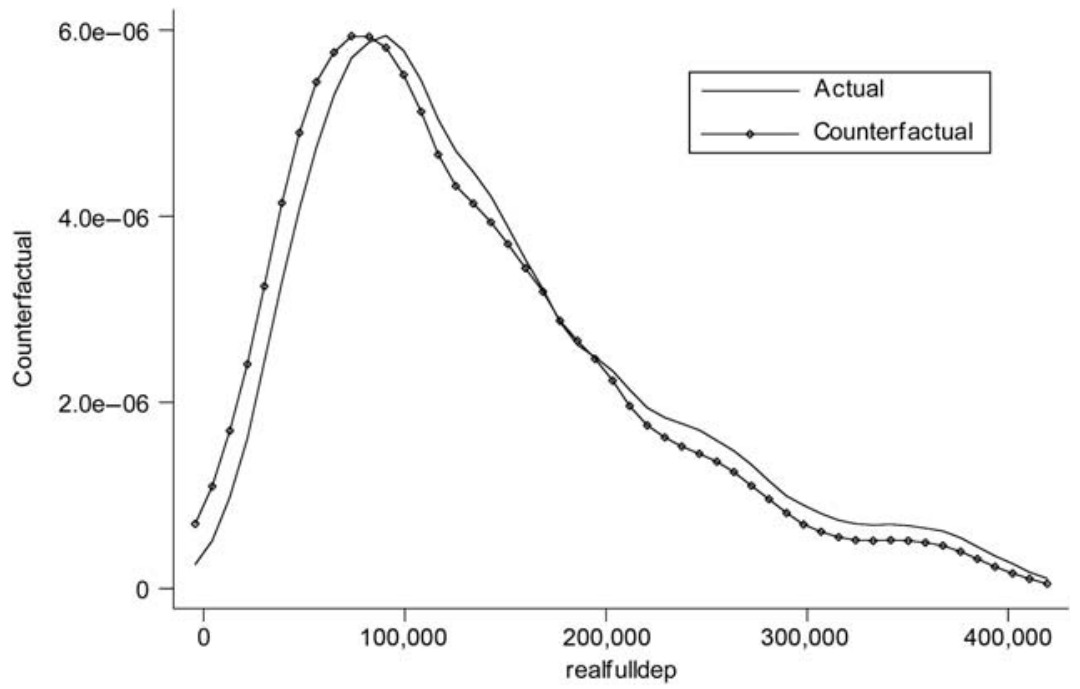

Figure 6: Kernel Density Estimates of Income Distribution, Vanilla Region. Source: Authors' calculations from EPM 2001 and simulations

Then, in a counterfactual experiment, we reduce the number of traders to a single one in Madagascar (i.e., we resuscitate the marketing board) and re-impose taxation at the pre-reform maximum rate of $82 \%$ during phase 2 . Resuscitating the marketing board in this framework generates implied FOB and producer prices consistent with this policy-imposed limited competition. The simulation gives new values for $\theta_{\mathrm{M}}, p_{\mathrm{M}}^{p}$ and $X_{\mathrm{M}}$ (the quantity of vanilla marketed by Madagascar), the latter two being fed to the household-survey data to generate a simulated income distribution. The inequality and poverty indices in the counterfactual column in Tables 6 and 7 are the result of this exercise. Figure 6 plots the actual and counterfactual kernel density estimates of the distribution of income in the vanilla region.

Under the counterfactual, depending on the assumption about elasticities, producer prices are reduced very sharply compared with their current values (Table A1). In percent of the current FOB price, the simulated producer price lies between 2 and $11 \%$, as

exporter allowed to ship fixed quantities of vanilla alongside the state marketing board. 
against $22 \%$ currently. The after-tax FOB price, by contrast, shoots up by a factor ranging between 2.3 and 4.4. This price increase is obtained by a sharp contraction of volumes exported, which go down by a factor between 3 and 6 . In accordance with intuition, Indonesian prices and volumes both go up (although by much less) as Indonesia free-rides on Madagascar's output restrictions.

How much of the counterfactual's lower producer price is attributable to the $82 \%$ export tax versus the change in the number of intermediaries? Multiplying $\theta_{\mathrm{M}}$ by 1.82 , we get $\tilde{\theta}_{\mathrm{M}}=(0.02)(1.82)=0.036$, so just eliminating the tax would have raised producer prices to $3.6 \%$ of the FOB price instead of $2 \%$; the bulk of the change between actual and counterfactual is thus attributable to the change in the number of intermediaries. These simulations, suggesting drastic effects on prices and quantities, no doubt provide upper bounds on the effect of change in the policy environment induced by the 1995 reforms.

Yet, as shown by the last columns of 5.1 and Figure 6, once re-introduced in the household survey, however, the new producer prices turn out to have a meek effect on the distribution of income. This is so because most of the effective consumption of Malagasy rural households is self-produced. Cash income represents at most $50 \%$ of income for the richest decile. Under the central assumption about elasticities reported in Table 6, the estimated change in the poverty headcount is that about 20,000 individuals were lifted out of poverty as a result of the 1995 reforms.

\section{Concluding Remarks}

The reforms initiated in 1993 (elimination of the VMB and phasing out of export taxes) put an end to decades of a policy of overexploitation of market power on the outside front and extortion of farmer incomes on the domestic. Our attempt to evaluate the effects of those reforms contains both good and bad news. On the positive front, intermediation margins fell following the dismantling of the VMB, and Madagascar has regained market share in the highquality natural-vanilla market with the help of major fires in its main competitor, Indonesia, and in spite of several adverse exogenous developments on the domestic front. But instability remains in the natural-vanilla market, and, more ominously, following the recent price hike, new entrants are appearing on the horizon, together 
with bio-engineered substitutes. It remains that little of this 'improvement' in the policy environment can be traced back to a noticeable producer response, both according to FAO data which suggest that yields and planted areas have remained about flat, after a small increase in 1996, and also from the econometric estimates based on household surveys. Inequality and poverty analysis from household surveys reveal a faint improvement in the vanilla regions relative to the rest of the rural areas along with more favourable wage and producer price changes than in the other regions.

To complement prima facie evidence, we turned to a counterfactual experiment to assess the effect of policy reform ceteris paribus. The results, again, contain good and bad news. Producer prices seem to have benefited from a substantial narrowing of intermediation margins after the reforms and phase-out of export taxes which stood in the early 1990s at extremely high levels. However, once introduced into household survey data, this improvement does not translate into large effects on measures of poverty and inequality simply because cash income from export crops is too small relative to self-consumption.

In a nutshell, thus, our main result is that the vanilla sector reforms may have had a large and positive effect on producer prices (travellers in the vanilla-producing region report a change in consumption to beer and to the purchase of durables like radios and bricks for construction), but the reductions in intermediation margins (i) were dwarfed by the volatility of world prices and (ii) did not have a large impact on farmers' welfare because of their extreme poverty, implying that cash income (including other cash crops) was less than half of household-imputed income.

For market reforms to take hold and make a difference for households in quasi-subsistence, impact effects will only be substantial when the economy 're-marketises', a process that takes time after decades of retrenchment under strongly anti-market policies. This is an important point that applies to several environments in SSA. In Madagascar, decades of bad policies and predatory taxation have raised transaction costs to such prohibitive levels that the market economy has largely shrunk to urban areas, leaving rural households isolated and forced to rely on themselves. Once this has happened, reforms affecting the price signals faced by rural farmers can only have small effects. Only 
over time, as rural economies re-marketise, can reforms be expected to have quantitatively large effects. This, of course, does not mean that they do not work: rather, that they take time and have increasing returns.

This case study suggests two further conclusions, the first relating to the difficult separation between malfunctioning markets due to excessive government intervention and that due to market failures. Thus, the reforms have created a regulatory vacuum in which unchecked concentration of intermediaries could occur again and lead to renewed exploitation of producers, although probably not to an extent comparable to what happened under CAVAGI. There is, indeed, anecdotal evidence that a large part of the price hike in 2004 was caused by strategic stockpiling between two large intermediaries in the sector.

Second, strategic behaviour in highly concentrated markets with informational failures can lead to largely undesired outcomes, at least from a national standpoint. Thus, when by 1993 the conditions that made reforms politically feasible were eventually met, rent extraction was largely exhausted and the world market had become increasingly contestable, as shown by the rising output of new producers. To use Margaret McMillan's expression (McMillan, 2001), by then the golden goose had already been killed.

\section{Acknowledgements}

The authors thank Ataman Aksoy, Céline Carrère, Marcelo Olarreaga and participants at seminars at CERDI, the University of Geneva, the World Bank and a referee for helpful comments. Remaining errors belong to the authors.

\section{References}

Baffes, J. (2005) 'The Cotton Problem', The World Bank Research Observer, 20 (1): 109-44.

Barrett, C. (1994) 'Understanding Uneven Agricultural Liberalisation in Madagascar', The Journal of Modern African Studies, 32 (3): 449-76.

Blarel, B. and D. Dolinsky (1995) 'Market imperfections and government failures: the vanilla sector in Madagascar', in S. Jaffe and 


\section{Olivier Cadot et al.}

J. Morton (eds), Marketing Africa's High-Value Foods; Comparative Experiences of an Emergent Private Sector. Dubuque, IA: Kendall/ Hunt Publishing Company, pp. 255-318.

Bohman, M., L. Jarvis and R. Barichello (1996) 'Rent-seeking and International Commodity Agreements: The Case of Coffee', Economic Development and Cultural Change, 44 (2): 379-404.

de Melo, J., M. Olarreaga and W. Takacs (2000) 'Pricing Policy under Double Market Power: Madagascar and the International Vanilla Market', Review of Development Economics, 4 (1): 1-20.

Ecott, T. (2004) Vanilla: Travels in Search of the Ice Cream Orchid. New York: Grove Press.

GOM (2003) 'Monographie de la région de la Sava', Ministry of Agriculture, Livestock and Fisheries, Madagascar, Unité de politique pour le développement rural, www.maep.gov.mg/fr/sava. pdf.

Hummels, D. and V. Lugovsky (2006) 'Are Matched Partner Trade Statistics a Usable Measure of Transport Costs?', Review of International Economics, 14 (1): 69-86.

Isham, J., M. Woolcock, L. Pritchett and G. Busby (2005) 'The Varieties of Resource Experience: Natural Resource Export Structures and the Political Economy of Economic Growth', World Bank Economic Review, 19 (2): 141-74.

Jaffe, S. and J. Morton (1995) Marketing Africa's High-Value Foods; Comparative Experiences of an Emergent Private Sector. Dubuque, IA: Kendall/Hunt Publishing Company.

Krueger, A., M. Schiff and A. Valdes (1988) 'Agricultural Incentives in Developing Countries: Measuring the Effect of Sectoral and Economywide Policies', World Bank Economic Review, 2 (3): 255-71.

McMillan, M. (2001) 'Why Kill the Golden Goose? A Political Economy Model of Export Taxation', Review of Economics and Statistics, 83 (1): 170-84.

McMillan, M., K. Horn and D. Rodrik (2004) 'When Economic Reform Goes Wrong: Cashews in Mozambique', Brookings Trade Forum 2003, 97-151.

Paternostro, S., J. Razafindronona and D. Stifel (2001) Changes in Poverty in Madagascar: 1993-1999, Cornell Food and Nutrition Policy Program Working Paper, 120. 
Péguy, O. (2003) Flambée des prix sur la vanille. Radio-France International, 22 September 2003, http://www.rfi.fr/actufr/ articles/045/articlelowbar;25068.asp.

Romani, M. (2003) Growth and Poverty in Madagascar, 19992001-Impact Analysis in a Context of Imperfect Data Comparability, mimeo. Oxford: Oxford University.

Sala-i-Martin, X. (1997) 'I Just Ran Two Million Regressions', American Economic Review, 87 (2): 178-83.

Schiff, M. and A. Valdes (1992) The Political Economy of Agricultural Pricing Policy: Volume 4, A Synthesis of the Economics in Developing Countries: A World Bank Comparative Study. Baltimore and London: Johns Hopkins.

World Bank (2001) Madagascar Diagnostic Trade Integration Study, mimeo, World Bank, Washington, D.C.

World Trade Organization (2002) Madagascar: Trade Policy Review, Geneva.

\section{Appendix A. The Simulation Model}

\section{A.1. The Model}

This appendix describes the partial equilibrium simulation model used for the counterfactual analysis of Section 4.2. Consider first a non-parameterised (general) formulation. Let $X_{M}$ and $X_{I}$ be the quantities of vanilla marketed by Madagascar and Indonesia, respectively. Let $P_{\mathrm{M}}$ be the world-market price of Malagasy vanilla and $p_{\mathrm{M}}^{P}$ its farmgate price. The inverse demand function for Malagasy vanilla is

$$
P_{i}=P_{i}\left(X_{\mathrm{M}}, X_{\mathrm{I}}\right) \quad i=\mathrm{M}, \mathrm{I}
$$

and the inverse supply is

$$
p_{i}=p_{i}\left(X_{i}\right)
$$

Let $x_{k}$ be the quantity of vanilla purchased and marketed by one of $n_{i}$ symmetric Malagasy (Indonesian) traders, so

$$
X_{i}=\sum_{k=1}^{n_{i}} x_{k} .
$$


Let $x_{-k}=\sum_{j \neq k} x_{j}$. The profit-maximisation problem of Madagascar's trader $k$ is

$$
\max _{x_{k}} \pi\left(x_{k \mathrm{M}}\right)=\left[P_{\mathrm{M}}\left(x_{k}+x_{-k}, X_{I}\right)-p_{\mathrm{M}}\left(x_{k}+x_{-k}\right)\right] x_{k}
$$

and similarly for the representative trader in Indonesia. Let $e_{k i}^{D} \equiv \mid \partial$ $\ln x_{k} / \partial \ln P_{i} \mid$ and $e_{k i}^{S}$ be, respectively, the price elasticities of demand and input supply facing trader $k$ in country $i$. Maximisation of equation (A1) gives a familiar expression equating marginal revenue with marginal input cost, namely

$$
\frac{P_{i}}{1+t_{i}}\left(1-\frac{1}{e_{k i}^{D}}\right)=p_{i}^{P}\left(1+\frac{1}{e_{k i}^{S}}\right)+c_{i},
$$

where $c_{i}$ is an intermediation cost, $p_{i}^{P}$ is the producer (farmgate) price and $t_{i}$ is the ad valorem export-tax rate, if any. Under symmetry of traders, $x_{k i}=X_{i} / n_{i}$, so letting $\varepsilon_{\mathrm{M}}^{D}$ and $\varepsilon_{\mathrm{I}}^{D}$ stand for the price elasticity of market demand in Madagascar and Indonesia, respectively, $e_{k i}^{D}=n_{i} \varepsilon_{i}^{D}$. Substituting in equation (A4) gives

$$
\frac{P_{i}}{1+t_{i}}\left(1-\frac{1}{n_{i} \varepsilon_{i}^{D}}\right)=p_{i}^{P}\left(1+\frac{1}{n_{i} \varepsilon_{i}^{S}}\right)+c_{i}, \quad i=\mathrm{M}, \mathrm{I} .
$$

It is easy to verify by implicit differentiation that the purchase price $p_{i}^{P}$ is an increasing function of the number of traders, $n_{i}$, and of the elasticity of supply. In the former case, the monopsony power of traders is reduced by large numbers, whereas in the latter it is reduced by a flat supply curve. Note that the presence of an export tax acts as if there was 'double marginalisation'. To see this, suppose that there were two layers of intermediaries, no intermediation cost and no tax. Using upper-case letters for the second layer of intermediaries, equation (A5) would then become

$$
P_{i}\left(1-\frac{1}{n_{i} \varepsilon_{i}^{D}}\right)=p_{i}^{P}\left(1+\frac{1}{n_{i} \varepsilon_{i}^{S}}\right)\left(1+\frac{1}{N_{i} E_{i}^{S}}\right) .
$$

Let $\tau=1 / \mathrm{N}_{i} E_{i}^{S}$. Then the presence of the second layer of intermediaries acts like an ad valorem export tax at rate $\tau$. 
In order to derive an expression for $\varepsilon_{i}^{D}$, we now parameterise the model. On the supply side, the farmers' vanilla supply is

$$
X_{i}^{S}=A_{i}^{S}\left(p_{i}^{p}\right)^{\varepsilon_{i}^{S}},
$$

where $p_{i}^{P}$ is the price paid to farmers, $\varepsilon_{i}^{S}$ is the price elasticity of the farmers' supply and $A_{i}^{S}$ is a calibration parameter. This function subsumes the behaviour of farmers, implicitly assuming some hoarding behaviour whose inter-temporal aspects we leave aside.

On the demand side, the overall utility is quasi-linear in vanilla $\left(X_{\mathrm{v}}\right)$ and an aggregate of all other goods $\left(X_{\mathrm{o}}\right)$ :

$$
U=X_{0}+\frac{1}{\tilde{A}_{\mathrm{v}}} X_{\mathrm{v}}^{\varepsilon_{\mathrm{v}}}-1 / \varepsilon_{\mathrm{v}}
$$

where $\tilde{A}_{\mathrm{v}}$ is a parameter, implying a constant marginal utility of income and a worldwide demand for vanilla of the form

$$
X_{\mathrm{v}}=A_{\mathrm{v}} P_{\mathrm{v}}^{-\varepsilon_{\mathrm{v}}} \text {, }
$$

$\varepsilon_{\mathrm{v}}$ being its constant price elasticity and $A_{\mathrm{v}}=\tilde{A}_{\mathrm{v}} \varepsilon_{\mathrm{v}} /\left(\varepsilon_{\mathrm{v}}-1\right)^{-\varepsilon_{\mathrm{v}}}$. The vanilla aggregate $X_{\mathrm{v}}$ has the familiar CES form:

$$
X_{\mathrm{v}}=A\left(\sum_{i} \beta_{i} X_{i}^{\rho}\right)^{\frac{1}{\rho}}=A\left(\sum_{i} \beta_{i} X_{i}^{1-1 / \sigma}\right)^{1 /(1-1 / \sigma)}
$$

$\rho=1-(1 / \sigma), \quad \sigma$ being the elasticity of substitution between Malagasy and Indonesian vanilla on the world market, and $A$ a calibration parameter fitted to reproduce aggregate vanilla expenditures in the base solution. Worldwide expenditure on vanilla is

$$
E=\sum_{i} P_{i} X_{i}
$$

Under the assumption of two-stage budgeting, equation (A10) can be maximised under constraint (A11) independently of upper-level choices (between $X_{0}$ and $X_{\mathrm{v}}$ ), giving a demand for variety $i$ equal to

$$
X_{i}=X_{\mathrm{v}} A^{\sigma-1} \beta_{i}^{\sigma}\left(\frac{P_{i}}{P_{\mathrm{v}}}\right)^{-\sigma},
$$

where

$$
P_{\mathrm{v}}=\frac{1}{A}\left(\sum_{i} \beta_{i}^{\sigma} P_{i}^{1-\sigma}\right)^{1 /(1-\sigma)}
$$




\section{Olivier Cadot et al.}

Under the assumption that traders play Cournot (by which is meant that they take as constant the quantities marketed by both their national and foreign competitors), it is easily verified that

$$
\frac{1}{\varepsilon_{i}^{D}}=\left.\frac{\partial \ln P_{i}}{\partial \ln X_{i}}\right|_{X_{-i} \text { constant }}=\frac{1}{\sigma}+\left(1-\frac{1}{\sigma}\right) s_{i},
$$

where $s_{i}$ is variety $i$ 's share of the worldwide vanilla market. This expression can then be substituted into equation (A5) to close the model.

\section{A.2. Calibration and Initial Equilibrium}

Intermediation cost data were provided to us by industry sources. Elasticities are based on the econometric estimates of de Melo et al. (2000). Their point estimates are (in algebraic form) $\hat{\varepsilon}_{M}^{\mathrm{D}}=-2.5$ for the own-price elasticity of demand for Malagasy vanilla, $\hat{\varepsilon}_{I}^{\mathrm{D}}=-1.99$ for the own-price elasticity of demand for Indonesian vanilla and $\hat{\varepsilon}_{M I}^{\mathrm{D}}=1.7$ for the cross-price elasticity, which they find, as expected, to be symmetric (in what follows, we ignore interaction with the artificial vanilla market). The elasticity of substitution can be retrieved from these estimates using the following decomposition:

$$
\begin{aligned}
\sigma & =\frac{\mathrm{d} \ln \left(X_{\mathrm{M}} / X_{\mathrm{I}}\right)}{\mathrm{d} \ln \left(P_{\mathrm{M}} / P_{\mathrm{I}}\right)}=\frac{\mathrm{d}\left(\ln X_{\mathrm{M}}-\ln X_{\mathrm{I}}\right)}{\mathrm{d}\left(\ln P_{\mathrm{M}}-\ln P_{\mathrm{I}}\right)} \\
& =\frac{\mathrm{d} \ln X_{\mathrm{M}}}{\mathrm{d}\left(\ln P_{\mathrm{M}}-\ln P_{\mathrm{I}}\right)}-\frac{\mathrm{d} \ln X_{\mathrm{I}}}{\mathrm{d}\left(\ln P_{\mathrm{M}}-\ln P_{\mathrm{I}}\right)} \\
& =\frac{1}{\left(\mathrm{~d} \ln P_{\mathrm{M}} / \mathrm{d} \ln X_{\mathrm{M}}\right)-\left(\mathrm{d} \ln P_{\mathrm{I}} / \mathrm{d} \ln X_{\mathrm{M}}\right)} \\
& -\frac{1}{\left(\mathrm{~d} \ln P_{\mathrm{M}} / \mathrm{d} \ln X_{\mathrm{I}}\right)-\left(\mathrm{d} \ln P_{\mathrm{I}} / \mathrm{d} \ln X_{\mathrm{I}}\right)} \\
& =\frac{1}{1 / \tilde{\varepsilon}_{\mathrm{M}}^{D}-1 / \tilde{\varepsilon}_{\mathrm{MI}}^{D}}-\frac{1}{1 / \tilde{\varepsilon}_{\mathrm{MI}}^{D}-1 / \tilde{\varepsilon}_{\mathrm{I}}^{D}}
\end{aligned}
$$

where tildes indicate that elasticities are in algebraic rather than absolute-value form. So $\hat{\sigma}=\left|\left(\frac{1}{-2.5}-\frac{1}{1.7}\right)-\left(\frac{1}{1.7}-\frac{1}{-1.99}\right)\right|=1.933$. In 
the simulations that follow, we use $\sigma=2$. Their estimate of the elasticity of supply is $\varepsilon^{S}=0.5$, which we apply to Indonesia as well.

To complete the calibration, by choice of units, let $\beta_{\mathrm{I}}=1-\beta_{\mathrm{M}}$, allowing us to dispose of the subscript on $\beta$. Likewise, normalise all prices to unity so that quantities can be extracted from the value data. Thus, with

$$
P_{\mathrm{v}}^{0}=1 \text { and } P_{i}^{0}=1 \quad \forall i .
$$

the price index for aggregate vanilla sales, $P_{\mathrm{v}}$ is equal to 1 . To obtain the calibrated equilibrium, the values for $n_{\mathrm{M}}$ and $n_{\mathrm{I}}$ are obtained by solving equation (A5) for $\varepsilon^{S}=0.5$ and $\sigma=2$ given observed markups gives $n_{\mathrm{M}}=5.12$ for Madagascar and $n_{\mathrm{I}}=9.58$ for Indonesia. These values are smaller than the actual number of traders but consistent with anecdotal evidence on Madagascar according to which about five large trading houses 'make the market'.

With parameters calibrated to replicate observed magnitudes as the initial equilibrium along the above lines, we have 10 equations in 10 unknowns given initial selling prices $P_{1}^{0}$ and $P_{2}^{0}$ (alternatively, one could fix initial producer prices or quantities). The eight endogenous variables determined in the system are $P_{\mathrm{v}}, X_{\mathrm{v}}, X_{\mathrm{M}}$, $\mathrm{X}_{\mathrm{I}}, n_{\mathrm{M}}, n_{\mathrm{I}}, p_{\mathrm{M}}^{P}$ and $p_{\mathrm{I}}^{P}$.

\section{A.3. Perturbation of the Initial Equilibrium and Results}

In the perturbed equilibrium, $n_{i}$ is fixed at a value that differs from its initial value, whereas $P_{\mathrm{M}}$ and $P_{\mathrm{I}}$ are freed. The number of equations and unknowns is thus unchanged. The values at which $n_{i}$ are fixed are, respectively, $\bar{n}_{\mathrm{M}}=1$ for Madagascar (monopsony/monopoly) and $\bar{n}_{\mathrm{I}}=n_{\mathrm{I}}$ for Indonesia (Cournot assumption-no entry), where $\mathrm{n}_{\mathrm{I}}^{*}$ is the number of traders at the initial equilibrium. We then recalculate equilibrium values for $P_{\mathrm{M}}, p_{\mathrm{M}}^{P}$, $P_{\mathrm{I}}, p_{\mathrm{I}}^{P}, X_{\mathrm{M}}$, and $X_{\mathrm{I}}$ (Table A1) consistent with the model's behavioural assumption (Cournot) and no entry in Indonesia. We then plug back the new values of $p_{\mathrm{M}}^{P}$ and $X_{\mathrm{M}}$ in the household survey's farmer-income data and recalculate the income distribution, poverty gap and poverty headcount. 
430 Olivier Cadot et al.

Results are reproduced in Table A1.

Table A1: Calibrated and Counterfactual Values

\begin{tabular}{|c|c|c|c|c|c|c|c|}
\hline \multicolumn{8}{|c|}{ Parameters } \\
\hline$\varepsilon_{\mathrm{V}}$ & 1 & & & & & & 2 \\
\hline$\varepsilon_{\mathrm{S}}$ & 0.5 & & 1 & & 2 & & 1 \\
\hline$\sigma$ & 2 & 4 & 2 & 4 & 2 & 4 & 2 \\
\hline \multicolumn{8}{|c|}{ Endogenous variables: calibrated values } \\
\hline$P_{\mathrm{M}}$ & 1.00 & 1.00 & 1.00 & 1.00 & 1.00 & 1.00 & 1.00 \\
\hline$p_{\mathrm{I}}^{P}$ & 1.00 & 1.00 & 1.00 & 1.00 & 1.00 & 1.00 & 1.00 \\
\hline$p_{\mathrm{M}}^{P}$ & 0.22 & 0.22 & 0.22 & 0.22 & 0.22 & 0.22 & 0.22 \\
\hline$p_{\mathrm{I}}^{P}$ & 0.42 & 0.42 & 0.42 & 0.42 & 0.42 & 0.42 & 0.42 \\
\hline$X_{\mathrm{M}}$ & 1,213 & 1,213 & 1,213 & 1,213 & 1,213 & 1,213 & 1,213 \\
\hline$X_{\mathrm{I}}$ & 458 & 458 & 458 & 458 & 458 & 458 & 458 \\
\hline $\bar{n}_{\mathrm{M}}$ & 5.12 & 4.86 & 4.20 & 3.94 & 3.74 & 3.48 & 4.20 \\
\hline$n_{\mathrm{I}}$ & 9.58 & 8.37 & 6.91 & 5.74 & 5.58 & 4.37 & 6.91 \\
\hline \multicolumn{8}{|c|}{ Endogenous variables: counterfactual values } \\
\hline$P_{\mathrm{M}}$ & 2.67 & 2.33 & 4.13 & 2.65 & 4.44 & 2.77 & 3.16 \\
\hline$p_{\mathrm{I}}^{P}$ & 1.61 & 1.77 & 1.79 & 1.88 & 1.83 & 1.92 & 1.39 \\
\hline$p_{\mathrm{M}}^{P}$ & 0.02 & 0.02 & 0.04 & 0.06 & 0.09 & 0.11 & 0.02 \\
\hline$p_{\mathrm{I}}^{P}$ & 0.31 & 0.37 & 0.38 & 0.40 & 0.39 & 0.40 & 0.21 \\
\hline$X_{M}$ & 383 & 383 & 216 & 306 & 196 & 281 & 121 \\
\hline$X_{\mathrm{I}}$ & 400 & 438 & 432 & 456 & 434 & 463 & 235 \\
\hline $\bar{n}_{\mathrm{M}}$ & 1.00 & 1.00 & 1.00 & 1.00 & 1.00 & 1.00 & 1.00 \\
\hline$n_{\mathrm{I}}$ & 9.58 & 8.37 & 6.91 & 5.74 & 5.58 & 4.37 & 6.91 \\
\hline
\end{tabular}

